\title{
MECHANICAL PROPERTIES OF CONCRETE WITH RECYCLED PLASTIC WASTE
}

\author{
Ashtar S. Al-LUHYBI ${ }^{1}$, Diyar N. QADER ${ }^{2, *}$ \\ ${ }^{1}$ Civil Department, Engineering College, University of Mosul, Mosul, Iraq. \\ 2 Department of Civil Engineering, Al-Qalam University College, Kirkuk, Iraq. \\ corresponding author: diyar.nasih@alqalam.edu.iq
}

\begin{abstract}
Plastics are a vast group of synthetic or semi-synthetic materials that are often made of polymers. Because of their plasticity, plastics can be molded, extruded, and pressed into solid objects of different sizes. Its extensive use is due to its flexibility, as well as a number of other properties such as light weight, durability, and low manufacturing costs. The high use of plastics has resulted in an increase in solid waste, with domestic waste accounting for a significant portion of it. Since this waste is not biodegradable and takes up a lot of space, it is considered a serious environmental problem. To overcome these adverse effects, recycling plastic waste and using it in concrete can be an effective way to protect the environment. In this study, an attempt was made to experimentally evaluate the mechanical properties of concrete with recycled PET plastic wastes. The effect of this type of plastic waste was investigated by adding it in three different lengths: $22 \mathrm{~mm}, 45 \mathrm{~mm}$, and a combination of both lengths $22+45 \mathrm{~mm}$. For each length of fiber, it was added in three percentages to concrete $0.1,0.3$ and $0.5 \%$ of cement weight. Several experiments were carried out on concrete mixtures such as slump test, compressive test, splitting tensile test, flexural test, and ultrasound pulse velocity test. The findings showed that PET waste in the form of fibers could be incorporated into concrete and achieve adequate compressive strength. When the ultrasound test results were compared to the results of previous tests, it was discovered that normal concrete containing plastic waste in the form of fibers performed exceptionally well.
\end{abstract}

\section{Keywords:}

PET fibers;

Experimental investigation; Mechanical properties; Ultrasound pulse velocity; Soil contamination.

\section{Introduction}

Plastic is one of the most important industrial materials whose use has increased tremendously and dramatically in recent years, as the use of this substance is increasing day by day. The reason for the increase in consumption of plastic is owing essentially to the advantages it possesses such as its light weight [1], durability, flexibility, low cost [2], low water absorption, stable dimensions, good resistance to chemicals except for alkalis [3]. This massive production and high consumption of plastics has led to the accumulation of solid waste, a large part of which is produced by domestic wastes [1]. As this waste is considered a real threat to the environment because it is not degradable and it occupies a large area of land fill. Another disadvantage of using it is that it causes obstruction of water drainage through the soil, which in turn leads to contamination of the soil with diseases caused by mosquitoes [4]. In addition, it negatively affects public health [1]. To overcome these problems, recycling plastic waste and using it in concrete can be an appropriate solution to preserve the environment [5]. Overall, there are many types of plastic waste used, but the most used type is polyethylene terephthalate (PET). Accordingly, PET is one of the most problematic plastic materials for the environment and the method of treating it through burning leads to the production of toxic gases that are harmful to human health [6]. Therefore, we see that many studies have trend towards making this material environmentally friendly by including it in concrete mixes. There are numerous studies 
that sought to investigate the effect of adding PET to concrete and in various manner, such as adding it as fine aggregate, flakes or by adding it as fibers to concrete. Also, there are other studies that have investigated the possibility of utilizing PET bottles by adding it in the form of resin and producing polymeric concrete.

[7] observed that using plastic waste as a partial substitute of fine aggregates at a rate of $20 \%$ led to a decrease in the slump and compressive strength by 25 an $72 \%$, respectively. [8] found that using PET waste as a partial replacement of sand produced a decrease in the workability, density, compressive strength, flexural, and splitting tensile strength. They also recorded decreases in modulus of elasticity as compared to traditional concrete [9] examined the effect of incorporating variable percentages of PET plastic fragments as a replacement of fine aggregate on the mechanical properties of concrete. Results indicated adding PET fragments with a percentage less than $10 \%$ contribute to increasing compressive, tensile, and flexural strength [10] concluded through their experimental study that examined the effect of adding plastic waste on the fresh properties of selfcompacting concrete that plastic waste might be used as a partial replacement of fine aggregates.

According to the investigation conducted by [6], it was concluded that the use of PET waste in a concrete mixture as irregular fiber results in an improvement of the compressive, tensile strength and modulus of elasticity. [3] observed an improvement in the mechanical characteristics of concrete when PET waste was incorporated with concrete as a fiber with varying ratios. The findings showed that adding PET fibers with $0.5 \%$ by weight of cement is the optimum ratio. In contrast to previous experiments, the findings of the experimental study conducted by [11] revealed that the addition of PET fibers led to a decrease in the compressive strength and elastic modulus. While its presence contributed to a delay in the emergence of cracks resulting from dry shrinkage. Similarly, the outcomes of the research carried out by Koo [12] proved that adding PET fibers decreases the compressive strength of the specimens relative to the control specimens.

According to the research works mentioned above, it can be observed that the behavior of concrete in cooperation with PET waste is not clear and that the findings are contradictory in this regard. Where it was found that studies have shown that PET waste has a positive impact on the characteristics of concrete. On the other hand, many studies demonstrated that adding it contributes to a deterioration in concrete behavior. Therefore, to understand the impact of adding PET waste on the properties of concrete, further studies and investigations are needed. Current research aims to focus on the possibility of using plastic fibers to produce environmentally friendly concrete. As well as evaluating the effect of PET waste on the performance of concrete with variable contents and sizes based on several factors, including (workability, compressive strength, splitting tensile strength, flexural strength and ultrasound pulse velocity). For this purpose, three different aspect ratios of PET waste $(27,55$, mixed aspect ratio) with various ratio infusion in concrete $(0,0.1,0.3,0.5 \%)$ were used.

\section{Experimental program}

\subsection{Materials}

\subsubsection{Cement}

A commercial Ordinary Portland cement locally available was employed in this study. It is conforming to Iraqi Standard Specification IQS NO.5 [13]. The chemical composition and physical properties of using cement are listed in Tables 1 and 2, respectively.

Table 1: Chemical composition of the ordinary portland cement.

\begin{tabular}{|c|c|c|}
\hline Property & Test result [\%] & Standard IQS, No. 5 \\
\hline Oxide composition & & \\
\hline Alumina, $\mathrm{Al}_{2} \mathrm{O}_{3}$ & 4.24 & \\
\hline Silica, $\mathrm{SiO}_{2}$ & 20.92 & \\
\hline Ferric Oxide, $\mathrm{Fe}_{2} \mathrm{O}_{3}$ & 3.76 & \\
\hline Lime, $\mathrm{CaO}$ & 59.81 & \\
\hline Sulphuric Anhydride, $\mathrm{SO}_{3}$ & 2.11 & Max. 2.8 \\
\hline Magnesia, $\mathrm{MgO}$ & 3.41 & Max. 5 \\
\hline
\end{tabular}




\begin{tabular}{|c|c|c|}
\hline Property & Test result [\%] & Standard IQS, No. 5 \\
\hline Compound composition & & \\
\hline $\mathrm{C}_{3} \mathrm{~A}$ & 4.89 & \\
\hline $\mathrm{C}_{2} \mathrm{~S}$ & 29.33 & \\
\hline $\mathrm{C}_{3} \mathrm{~S}$ & 40.63 & \\
\hline $\mathrm{C}_{4} \mathrm{AF}$ & 11.44 & \\
\hline Free Lime & 0.97 & \\
\hline Loss on ignition & 2.22 & Max. 4 \\
\hline Solid solution & 15.31 & \\
\hline Insoluble Residue & 1.38 & \\
\hline
\end{tabular}

Table 2: Physical properties of the used cement.

\begin{tabular}{|c|c|c|}
\hline Property & Test result & Standard IQS, No. 52015 \\
\hline Initial setting time [min] & 120 & $\geq 45$ \\
\hline Final setting time [min] & 240 & $\leq 600$ \\
\hline \multicolumn{3}{|c|}{ Compressive strength [MPa] } \\
\hline at 3 days & 34.9 & $\geq 15.0$ \\
\hline at 7 days & 38.1 & $\geq 23.0$ \\
\hline
\end{tabular}

\subsubsection{Fine aggregate}

Clean river sand with maximum aggregate size of $4.75 \mathrm{~mm}$ was used as a fine aggregate. The results of the sieve analysis test show that the grading of fine aggregates complies with the limits of the ASTM C33 specification [14]. The grading and physical properties are illustrated in Tables 3 and 4, respectively.

Table 3: Physical properties of fine aggregate.

\begin{tabular}{|c|c|}
\hline Type of fine aggregate & Medium sand \\
\hline Color & Brown \\
\hline Specific Gravity S.S.D basis & 2.68 \\
\hline Absorption & 1 \\
\hline Compact unit weight $\left[\mathrm{kg} / \mathrm{m}^{3}\right]$ & 1981 \\
\hline Loose unit weight $\left[\mathrm{kg} / \mathrm{m}^{3}\right]$ & 1833 \\
\hline Fineness modulus & 3.02 \\
\hline
\end{tabular}

Table 4: Sieve analysis of fine aggregate.

\begin{tabular}{|c|c|c|}
\hline Sieve size [mm] & \% Specification limits according to ASTMC33-99a & Passing of used sample [\%] \\
\hline 4.75 & $89-100$ & 99.5 \\
\hline 2.36 & $60-100$ & 78 \\
\hline 1.18 & $30-100$ & 58 \\
\hline 0.6 & $15-100$ & 40.5 \\
\hline 0.3 & $5-70$ & 16 \\
\hline 0.15 & $0-15$ & 6 \\
\hline
\end{tabular}

\subsubsection{Coarse aggregate}

A river rounded gravel with a maximum aggregate size of $19 \mathrm{~mm}$ was used in this study. The results of sieve analysis test reveal that the grading of coarse aggregates is in accordance with ASTM C33 specification limits [14]. Tables 5 and 6 display the grading and properties of normal coarse aggregate. 
Table 5: Grading of normal coarse aggregate.

\begin{tabular}{|c|c|c|}
\hline \multicolumn{3}{|c|}{ Grading of coarse aggregate M.A.S 20 mm } \\
\hline Sieve size [mm] & Specification limits according to ASTM-C33-99a [\%] & Passing of used sample [\%] \\
\hline 25 & 100 & 100 \\
\hline 19 & $90-100$ & 95 \\
\hline 9.5 & $20-55$ & 38 \\
\hline 4.75 & $0-10$ & 0 \\
\hline 2.36 & $0-5$ & 0 \\
\hline
\end{tabular}

Table 6: Properties of coarse aggregate.

\begin{tabular}{|c|c|}
\hline Type of coarse aggregate & Rounded gravel \\
\hline Specific gravity S.S.D & 2.63 \\
\hline Absorption [\%] & 0.25 \\
\hline Compact unit weight $\left[\mathrm{kg} / \mathrm{m}^{3}\right]$ & 1087 \\
\hline Loose unit weight $\left[\mathrm{kg} / \mathrm{m}^{3}\right]$ & 1689 \\
\hline Angularity index & 0.74 \\
\hline
\end{tabular}

\subsubsection{PET fiber}

PET wastes were prepared by collecting mineral water bottles and excluding the neck and bottom of the bottle and removing the trademarks applied to it to obtain a homogeneous fiber. Thereafter, the bottles were cut into fibers with a constant thickness of $0.13 \mathrm{~mm}$. Three different fiber sizes were used in this research work. The first with a length and width of approximately 45 and $4 \mathrm{~mm}$, respectively. The second with a length and width of approximately 22 and $4 \mathrm{~mm}$, respectively. While the third was a mix of the previous two sizes $45 \mathrm{~mm}$ and $22 \mathrm{~mm}$. Fig. 1 shows the shapes of shredded PET fibers waste.
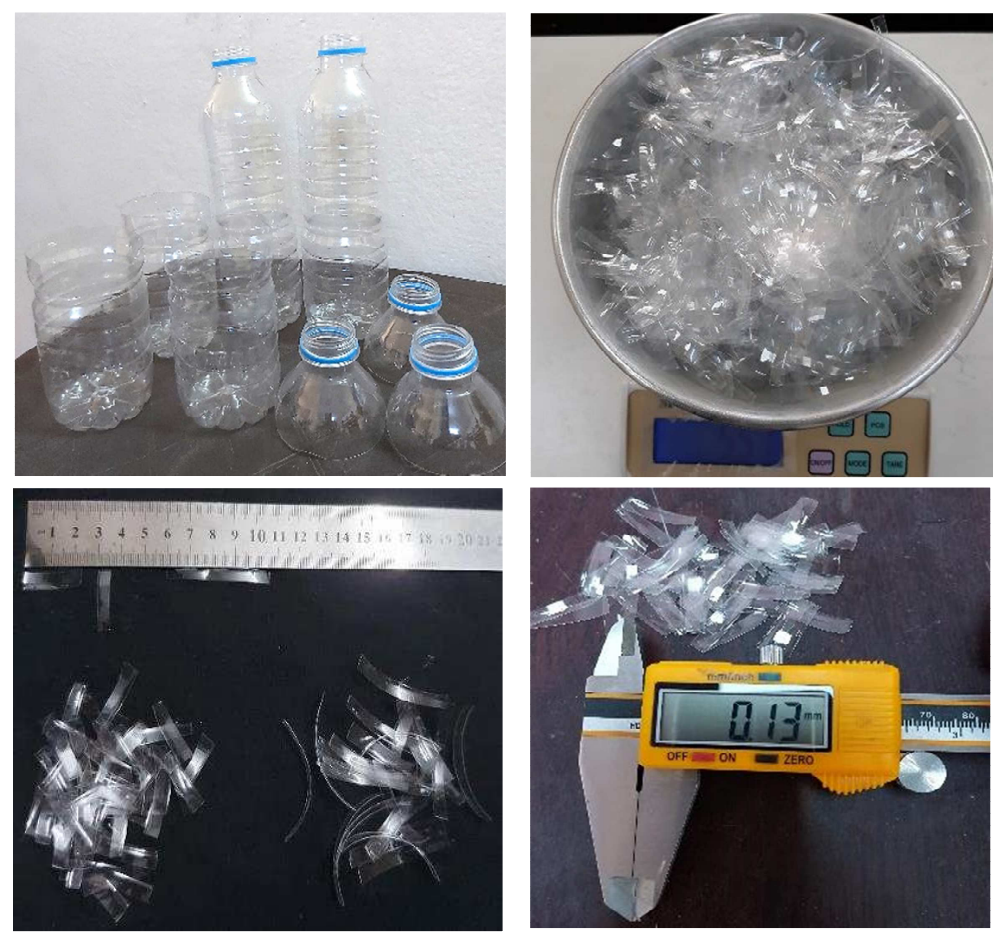

Fig. 1: PET waste fibers used in this study.

\subsection{Concrete mixes and experimental tests}

In the current study, 10 concrete mixtures were cast with weight ratios (cement: sand: gravel) that are 1:2: 4 and with a water/cement ratio of 0.58 . The materials used in preparing the concrete mixes were in dry condition. One of the mixes was without plastic fibers, as it is considered the 
reference mix. The other 9 mixtures were divided into three groups, the only variables were the dimensions of the plastic fibers. The first group contains plastic fibers with $45 \mathrm{~mm}$ length and consists of three mixes in which the variable is the percentage of the plastic fibers $0.1,0.3$, and $0.5 \%$ of the cement weight. The second group contains plastic fibers with a length of $22 \mathrm{~mm}$ that having three mixes with different ratios of plastic fibers. The last group was the combination of the two previous fiber lengths 45 and $22 \mathrm{~mm}$, respectively, which also consists of three mixes in which the only variable is the proportion of the plastic fibers. Table 7 lists the proportions of concrete mixes and plastic fiber dosages. In order to obtain the compressive strength of all concrete mixtures, concrete cubes with dimensions of $100 \times 100 \times 100 \mathrm{~mm}$ were prepared. Afterwards, the test was conducted according to the specifications BS 1881: Part 116 [15] for different curing periods 3, 7, 28 and 56 days in which three samples were tested for each curing period and their average was then calculated. While for the tensile strength and flexural strength of the mixtures, two concrete cylinders of dimensions $100 \times 200$ $\mathrm{mm}$ were cast for each percentage of the added fibers and three concrete prisms $100 \times 100 \times 500$ $\mathrm{mm}$, and the average values were calculated. These tests were conducted on the samples at age 28 days according to ASTM C496/C496 M and ASTM C293/C293 M [16, 17].

Table 7: Concrete mixture proportion details.

\begin{tabular}{|c|c|c|c|c|c|c|}
\hline Group & $\begin{array}{c}\text { PET fibers } \\
{[\%]}\end{array}$ & $\begin{array}{l}\text { Cement } \\
{\left[\mathrm{kg} / \mathrm{m}^{3}\right]}\end{array}$ & $\begin{array}{c}\text { Sand } \\
{\left[\mathrm{kg} / \mathrm{m}^{3}\right]}\end{array}$ & $\begin{array}{r}\text { Gravel } \\
{\left[\mathrm{kg} / \mathrm{m}^{3}\right]}\end{array}$ & $\begin{array}{r}\text { Water } \\
{\left[\mathrm{kg} / \mathrm{m}^{3}\right]}\end{array}$ & Mix proportion \\
\hline Control & 0 & 300 & 600 & 1200 & 174 & \multirow{10}{*}{ 1: $2: 4: 0.58$} \\
\hline \multirow{3}{*}{$\begin{array}{c}\text { Group } 1 \text { (fiber length = } \\
45 \mathrm{~mm} \text { ) }\end{array}$} & 0.1 & 300 & 600 & 1200 & 174 & \\
\hline & 0.3 & 300 & 600 & 1200 & 174 & \\
\hline & 0.5 & 300 & 600 & 1200 & 174 & \\
\hline \multirow{3}{*}{$\begin{array}{c}\text { Group } 2 \text { (fiber length }= \\
22 \mathrm{~mm})\end{array}$} & 0.1 & 300 & 600 & 1200 & 174 & \\
\hline & 0.3 & 300 & 600 & 1200 & 174 & \\
\hline & 0.5 & 300 & 600 & 1200 & 174 & \\
\hline \multirow{3}{*}{$\begin{array}{c}\text { Group } 3 \text { (fiber length }= \\
45+22 \mathrm{~mm} \text { ) }\end{array}$} & 0.1 & 300 & 600 & 1200 & 174 & \\
\hline & 0.3 & 300 & 600 & 1200 & 174 & \\
\hline & 0.5 & 300 & 600 & 1200 & 174 & \\
\hline
\end{tabular}

\section{Results and discussion}

\subsection{Slump test results}

The overall results of the slump test for all concrete mixes and for all ratios of plastic fibers added, which were carried out according to ASTM C143 [18] are shown in Fig. 2. Based on Fig. 2, it can be clearly observed that the addition of P ET wastes has a negative effect on the workability of the concrete mixtures and this conclusion has been drawn by many researchers [8, 19]. The concrete mixture containing $0 \%$ of PET wastes has the highest slump value of $120 \mathrm{~mm}$, and with the addition of PET wastes, the workability gradually decreased.

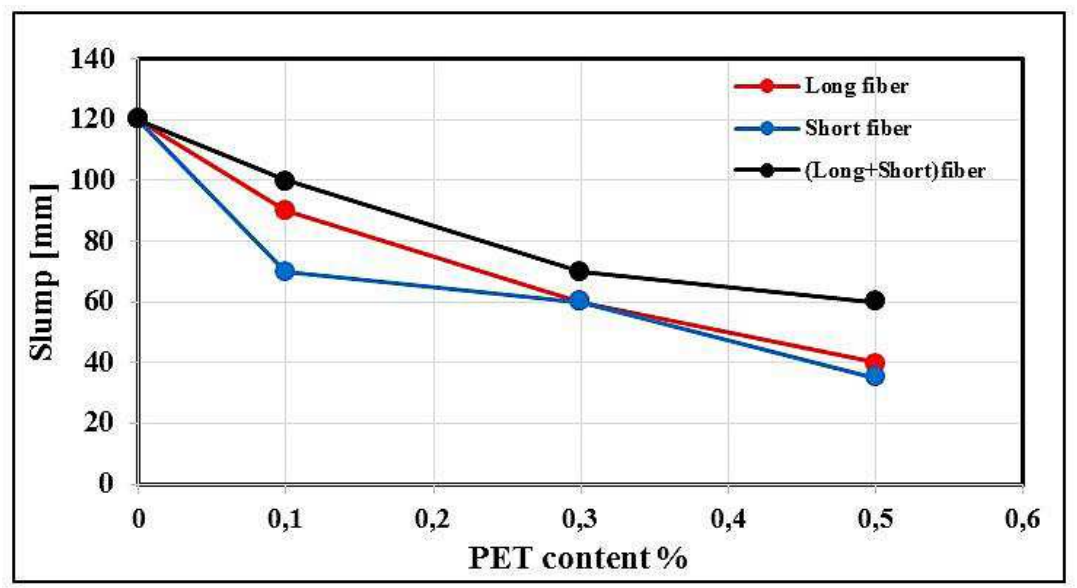

Fig. 2: Slump test results. 
The results also show that the workability of concrete decreases with increasing the percentage of addition of PET wastes. The amount of reduction in the slump value, when adding the long fibers, reached 25,50 , and $66.7 \%$ for the corresponding ratios of $0.1,0.3$, and $0.5 \%$, respectively. While for the short fibers, the amount of decrease in the sump value was $41.7,50$, and $70.8 \%$ for the proportions $0.1,0.3$, and $0.5 \%$, respectively. Finally, the decrease in the amount of slump for the mixed fibers (long + short) was $16.7,41.7$, and $50 \%$ for the ratios $0.1,0.3$, and $0.5 \%$, respectively. The reason for the reduction in the amount of slump compared to the control mix is attributed to the fact that the presence of plastic fibers waste works to restrict the concrete flow and movement of aggregates. Moreover, the addition of plastic wastes at high rates creates workability problems due to its large surface area [20], as it easily absorbs the cement paste, which leads to an increase in the viscosity of the concrete mixture [21]. As for the effect of the length of the fibers, there was no remarkable variation, since, the long and short fibers led to almost a same reduction in the slump value. While comparing their effect to the same weight ratio, the long fibers prevent the transport of aggregate. As for the short fibers, their number will be more even though the weight is constant and therefore its effect on the concrete flow will almost be the same effect of long fibers. When the two types of fibers were combined and added to the concrete, this led to an improvement in the workability of the concrete as the amount of decrease in slump was less. It is worth noting that the addition of plastic wastes made the concrete mixture more stable and constant and increased its cohesion, but with negative impact on its ability to flow, as shown in Fig. 3. Also, the presence of plastic waste fibers prevents the occurrence of separation inside the concrete mix [22].
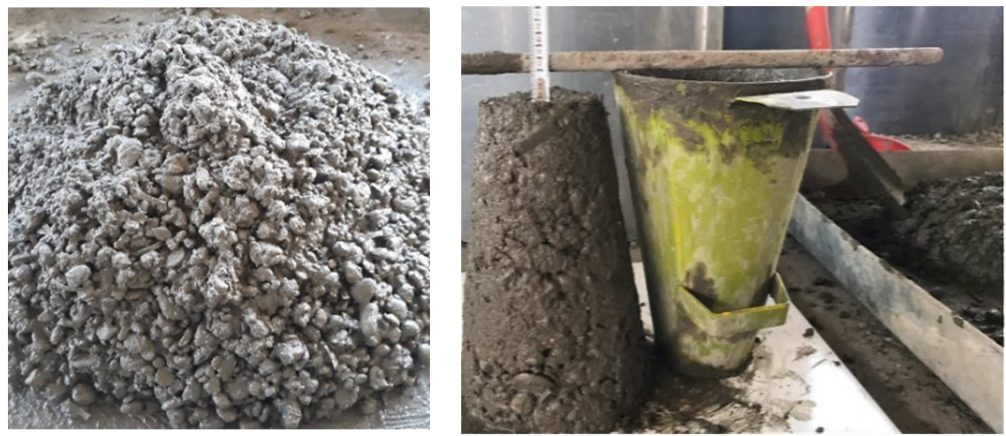

Fig. 3: Slump test and concrete flow.

\subsection{Concrete compressive test results}

The concrete compressive strength results for curing periods $3,7,28$, and 56 days and for added PET wastes with different proportions are shown in Figs. 4-6. It can be noticed from the results that the addition of PET wastes has a slight effect on improving the compressive strength of concrete. The results of previous research studies revealed that the addition of this material tends to increase the compressive strength up to a certain percentage, and then by increasing its percentage, the compressive strength of the concrete decreases.

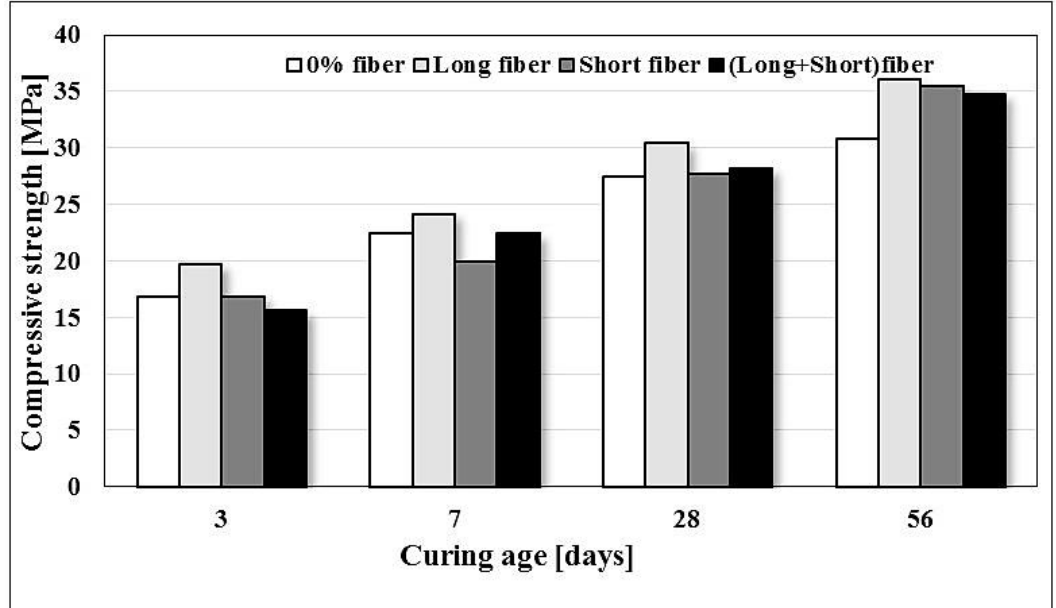

Fig. 4: Compressive strength of concrete containing $0.1 \%$ PET fiber. 


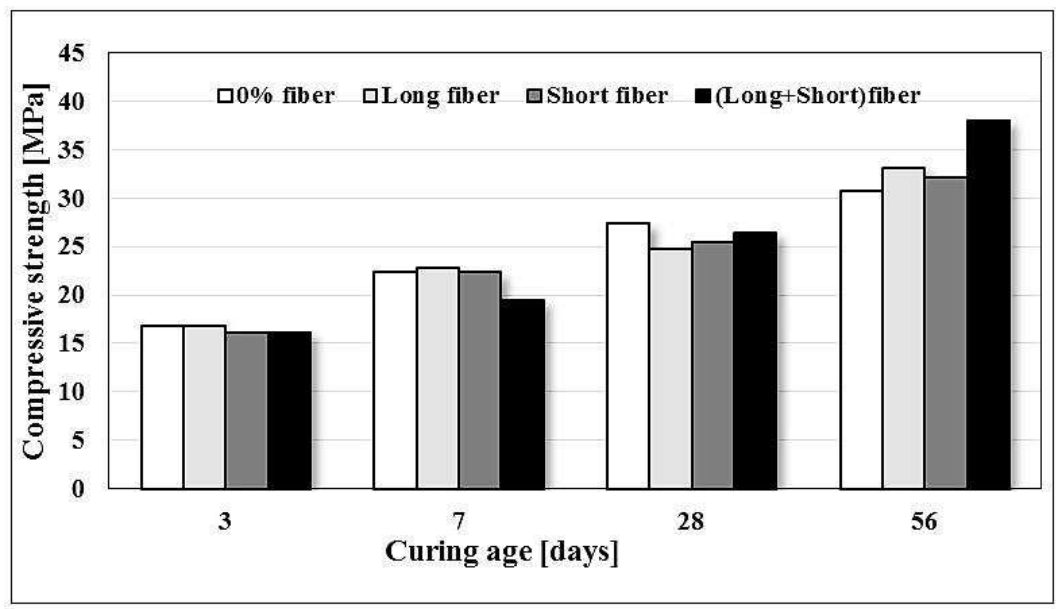

Fig. 5: Compressive strength of concrete containing $0.3 \%$ PET fiber.

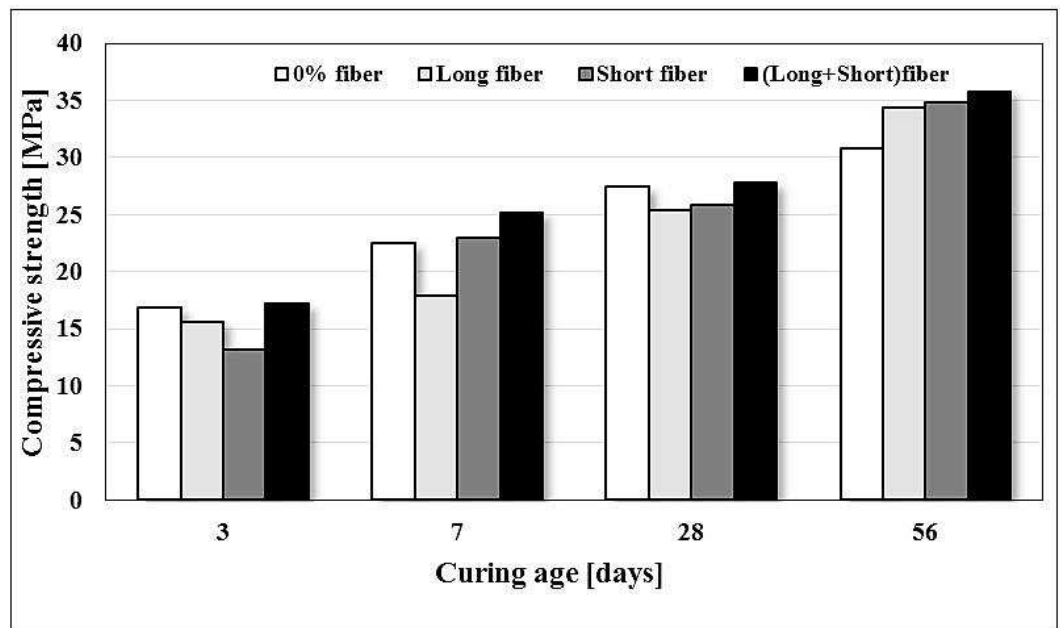

Fig. 6: Compressive strength of concrete containing $0.5 \%$ PET fiber.

The addition of $45 \mathrm{~mm}$ PET wastes to the concrete mixture at a rate of $0.1 \%$ of the cement weight led to an increase in the compressive strength up to 10.8 and $17.2 \%$ at curing ages 28 and 56 days, respectively as compared to the reference mixture. Whereas, the addition of PET wastes at a ratio higher than $0.1 \%$ led to a reduction in the compressive strength by 9.5 and $16.7 \%$ corresponding to 0.3 and $0.5 \%$ of fiber wastes, respectively, at age of 28 days. Likewise, when adding plastic waste fibers with a length of $22 \mathrm{~mm}$, these fibers increased the compressive strength up to 0.9 and $15.2 \%$ when added by $0.1 \%$, at ages 28 and 56 days, respectively. Thus, the increase in the addition ratio of PET wastes decreased the compressive strength of the concrete mixes. Similarly, it can be seen that adding plastic fiber wastes in the form of a combination of the two previous sizes 45 $+22 \mathrm{~mm}$ increases the compressive strength when adding fibers by $0.1 \%$, as the increase in compression strength reached 2.8 and $13 \%$ at the ages of 28 and 56 days, respectively. The reason for this reduction in the compressive strength of concrete containing plastic fiber wastes is attributed to the weak bonding and interaction between the smooth surface of the fibers and the cement paste. Moreover, the plastic waste is characterized by not absorbing water, which in turn will impede the penetration of water into the concrete and thus affect the cement rehydration process [23].

Besides, it can be observed from figures, is that all mixtures have the same trend as the compressive strength increases with age. This is due to the rehydration process because the longer the curing period, this means the continuation of a CSH gel formation, which leads to an increase in compressive strength with age. When comparing the mixtures having an addition ratio of $0.1 \%$ of the cement weight, it can be noticed that mixtures containing long plastic fibers have the highest values of compressive strength at all ages. While, the increase in the addition amount of these fibers leads to a decrease in the compressive strength values. This might be attributed to that the long plastic fibers tend to clump together more than short fibers [19]. Thus, these will be weak characteristics as they are 
acting as the voids and hence affect the density of concrete, which negatively influences the compressive strength, as shown in Fig. 7.

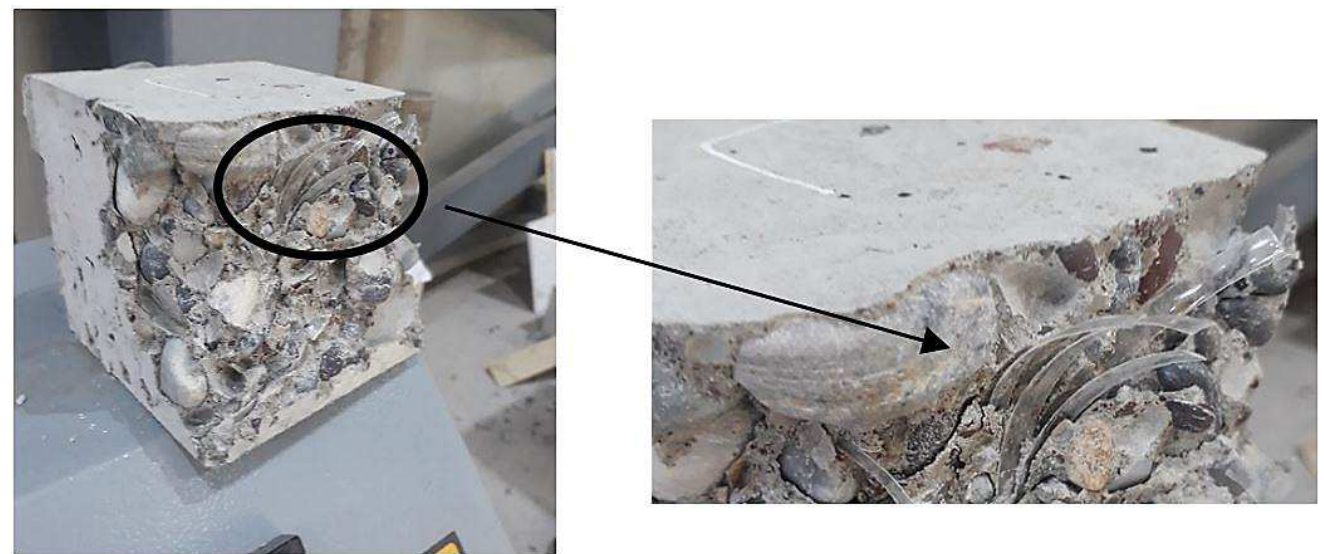

Fig. 7: Clumping of long fibers inside the concrete.

While for the addition ratios of 0.3 and $0.5 \%$, it is obvious that the compressive strength of mixtures containing mixed lengths of both long and short plastic fibers is better than the other two mixture types. This is because adding fibers of different lengths will have better spread and dispersion inside concrete than adding long fibers only. In addition to that, the different lengths of plastic fibers will act as bridges to connect and prevent the formation of micro cracks.

\subsection{Concrete tensile test results}

Indirect concrete tensile strength was measured by performing a splitting tensile strength test of concrete. The test results at the age of 28 days showed that the tensile strength of concrete containing PET fibers revealed a clear reduction for all fiber lengths and for all addition ratios, as shown in Fig. 8.

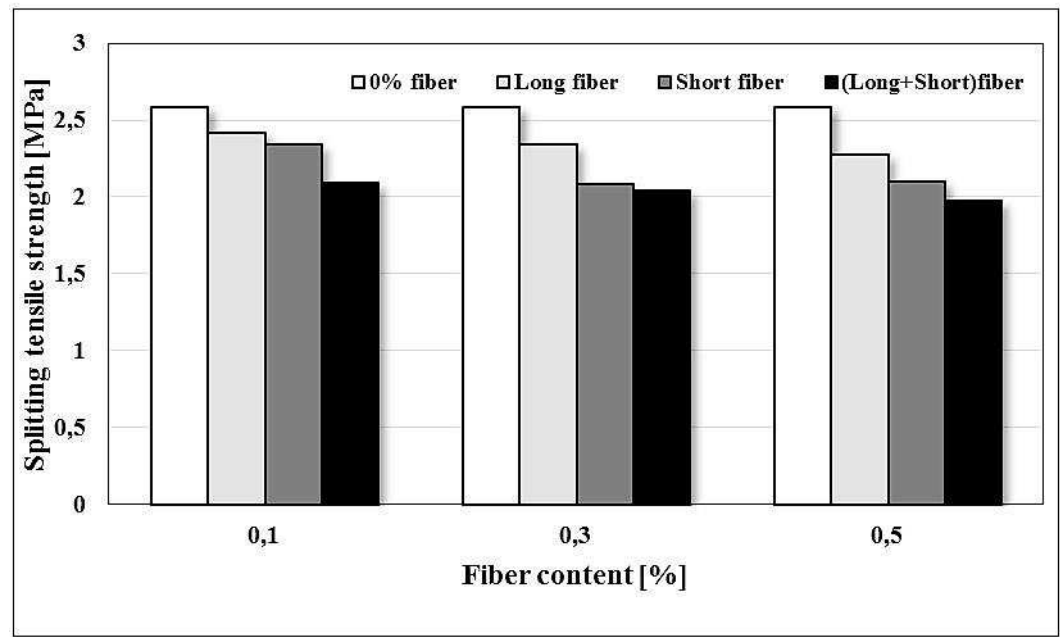

Fig. 8: Relationship of splitting tensile strength with different fiber proportions.

The decrease in the mixtures containing the long fibers compared to the reference mixture 6.5 , 9.6 , and $12 \%$ for the addition ratios $0.1,0.3$, and $0.5 \%$, respectively. While the reduction in the tensile strength of the mixtures with short fibers reached $9.6,19.4$, and $18.8 \%$ for the ratios $0.1,0.3$, and 0.5 $\%$, respectively. It was also noticed that the most significant decrease in the tensile strength values occurred when adding the hybrid (long+short) fibers, which reached 19.17, 21.3, and $23.7 \%$ when adding the fibers in proportions of $0.1,0.3$, and $0.5 \%$, respectively. The reason for this is the smooth surface of the fibers, which in turn leads to a weak bond between the PET fibers and the cement paste [24], and this leads to weaken the interaction with concrete components.

The images in Fig. 9 are taken with a microware digital microscope and with a magnification of 1-600 X. However, it is clear from the Fig. 9 a, b and $c$ how the fibers are interconnected with 
concrete, which is imperative when using these fibers to roughen the surface in order to improve their interlocking with the cement paste, especially the short fibers. Fig. $9 \mathrm{~d}$ shows the location of the fibers after they separated from their place due to the weak bond between the fibers and the cement paste.
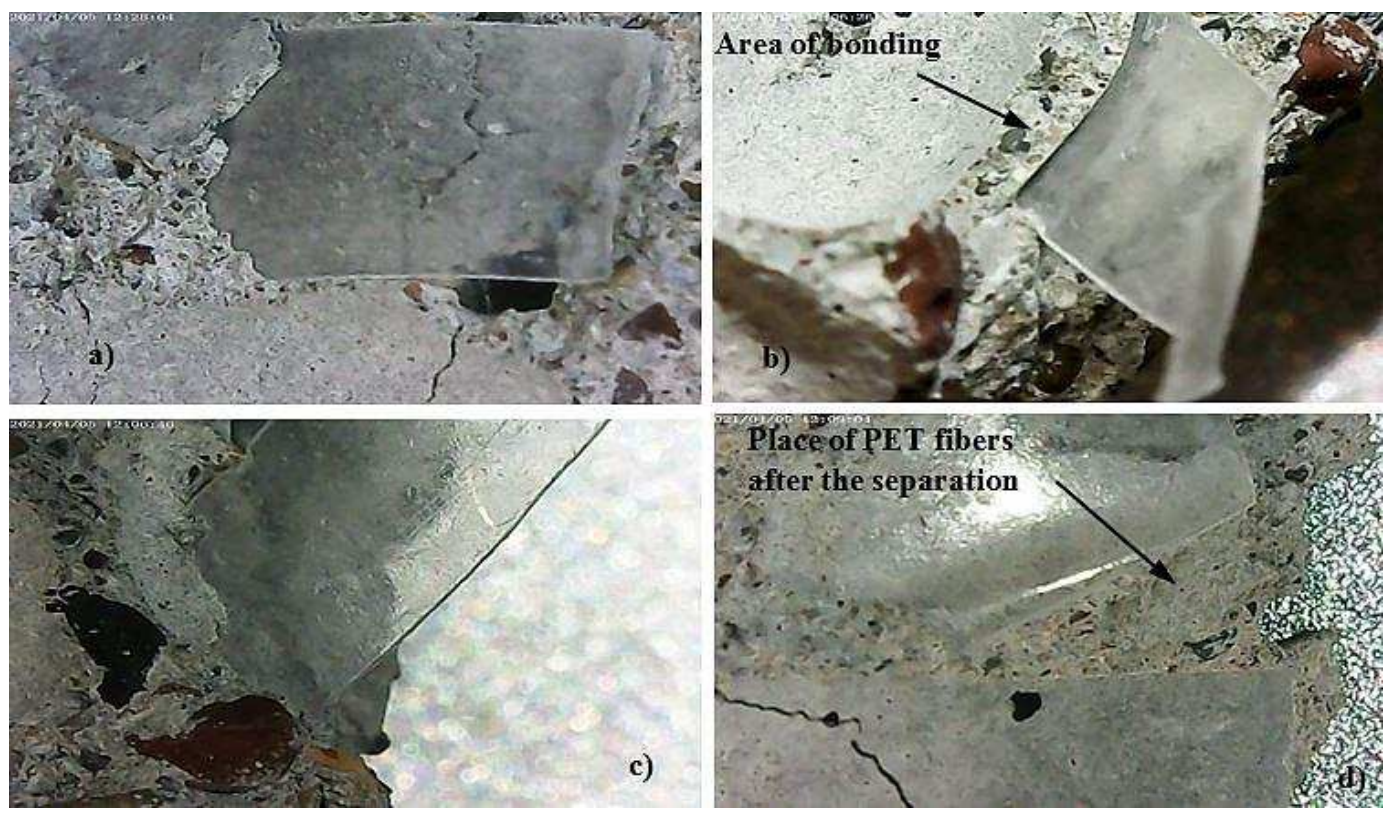

Fig. 9: Separation of PET fibers.

Based on the outcomes, it can be observed that although the addition of the long fiber $45 \mathrm{~mm}$ caused a decrease in the tensile strength of concrete, its results showed the highest results in tensile strength compared to the rest of the fiber lengths. This means that this length has a more effect on the resistance of the pull out force [25]. It can also be noticed that by increasing the percentage of PET wastes addition, the decrease in the tensile strength of concrete mixtures increases, and this gives an indication that there are clumps of fibers formed within the mixture as a result of not spreading it regularly. It is worth noting that the failure of the cylinders of the reference mixture was sudden. While the PET fibers worked to enhance the failure mode by transforming it from brittle to ductile and retaining the original shape even after the cracks formed, as the presence of fibers in the concrete limits the divisions and acts as a fracture inhibitor [26], as shown in Fig. 10.

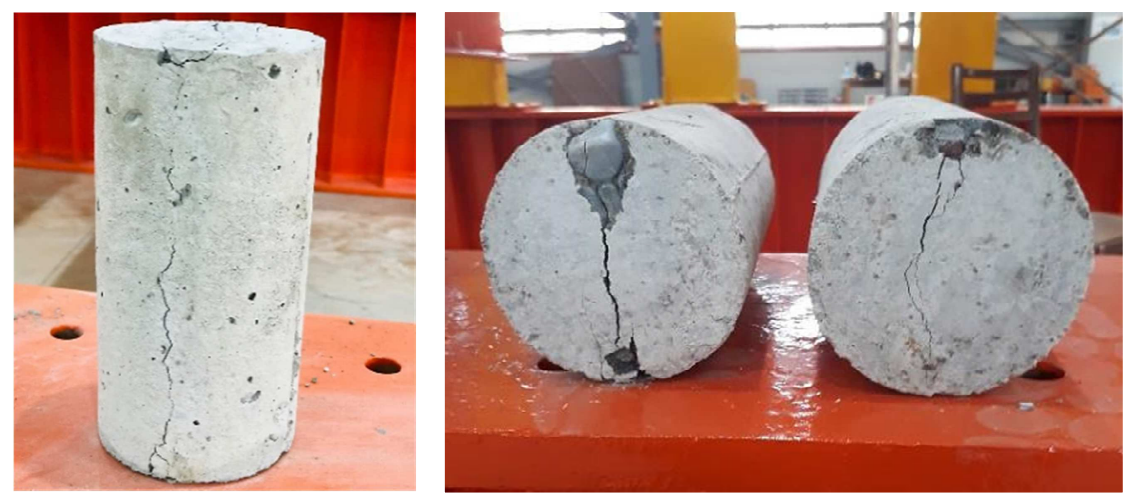

Fig. 10: Failure mode of concrete cylinders.

\subsection{Flexural strength test results}

This test was carried out on three point prism specimens, and by observing the results shown in Fig. 11. It is evident that the addition of PET fibers led to an improvement in the flexural strength of all fiber lengths particularly with a ratio of $0.1 \%$ because they acted as bridges. But after this percentage, the flexural strength showed a decrease with the increase in the percentage of PET fiber. This is because that the increase in the inclusion of these fibers leads to a weak bond between the fibers and the concrete components. 


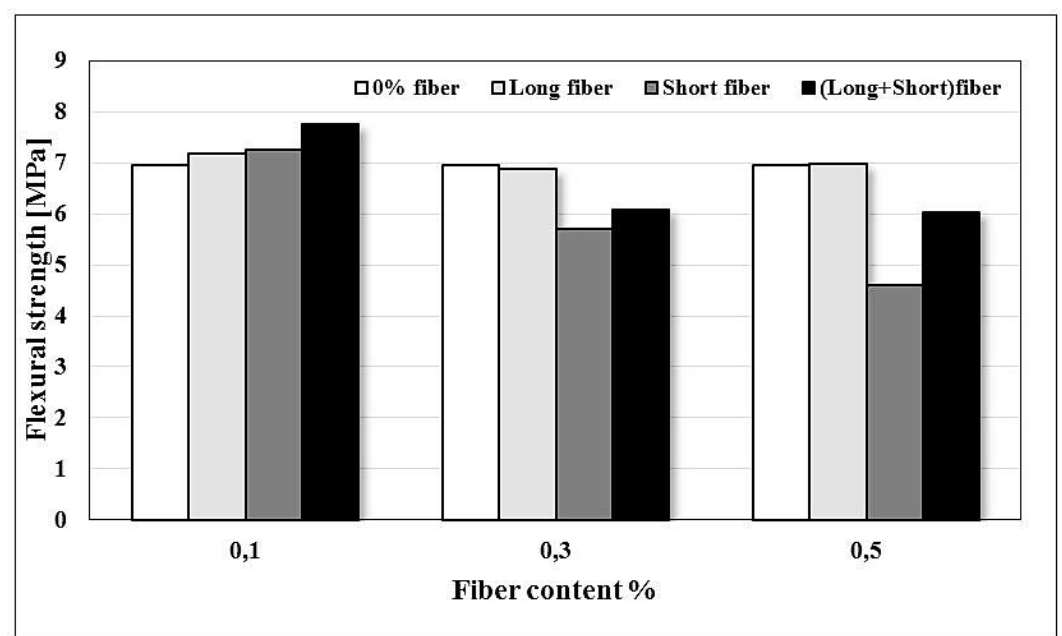

Fig. 11: Relationship of flexural strength with different fiber proportions.

The rates of increase in flexural strength at $0.1 \%$ addition for long, short and hybrid fibers reached $3,4.2$ and, $10.2 \%$, respectively. Also, the flexural strength of the hybrid fibers at this ratio is better than the rest of the other fiber lengths, and this is due to the fact that the combination of the two lengths works to integrate and bind the concrete better. But by increasing the addition percentage, this reduces the resistance of concrete significantly. It is also noticed from the results that mixtures containing long fibers experience a reduction in addition rates higher than $0.1 \%$, but the percentage of decrease is less. So that at an addition ratio of $0.5 \%$, the flexural strength values of the reference mixture and the mixture containing long fibers are almost equal. This is because, as mentioned earlier, long fibers have a higher pull out resistance. It can also be observed that the decrease when adding short fibers is higher than the rest of the types, and this is likely to occur due to the accumulation of fibers and not spreading regularly within the concrete mixture.

The addition of PET fibers also affected the failure mode of the specimens as it changed it from brittle and sudden failure to ductile failure, especially in the post-crack region. This is because these fibers absorb stress after the concrete reaches its tensile strength as it works to tighten the concrete texture and as an integral piece. The failure occurs by bending the concrete specimen, but without a sudden collapse of the model, as is the case in plain concrete [22]. Fig. 12 shows the failure mode for samples containing PET fibers.

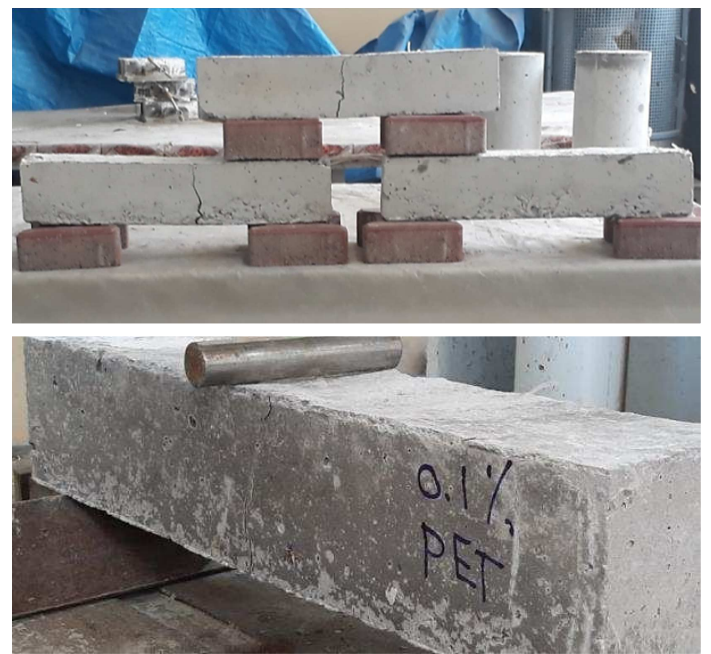

Fig. 12: Failure mode of concrete prism containing PET fibers.

\subsection{Ultrasound pulse velocity test results}

Ultrasound pulse velocity (UPV) test is considered one of the non-destructive tests used to determine concrete strength and assess its quality. This test is affected by the density of concrete and internal cracks [27]. The principle of this test is based on measuring the time taken to pass an 
ultrasound wave through the material [28]. As shown in the Fig. 13, the ultrasound velocity was measured for compressive specimens, which are cubes with dimensions $100 \times 100 \times 100 \mathrm{~mm}$ and ages of 28 and 56 days.

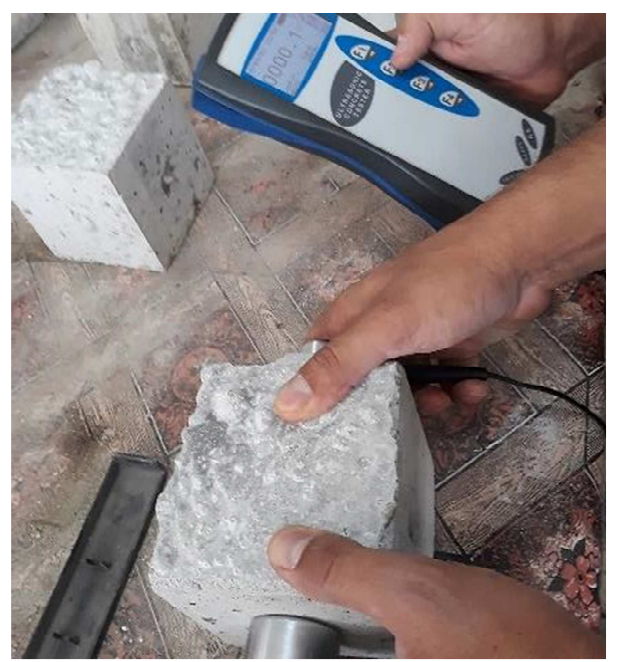

Fig. 13: Ultrasound velocity test on compressive concrete specimens.

Figs. 14 and 15 show the velocity of the ultrasound waves for all lengths, for all proportions, and at ages 28 and 56 days. The presented results are an average of three samples for each mixture.

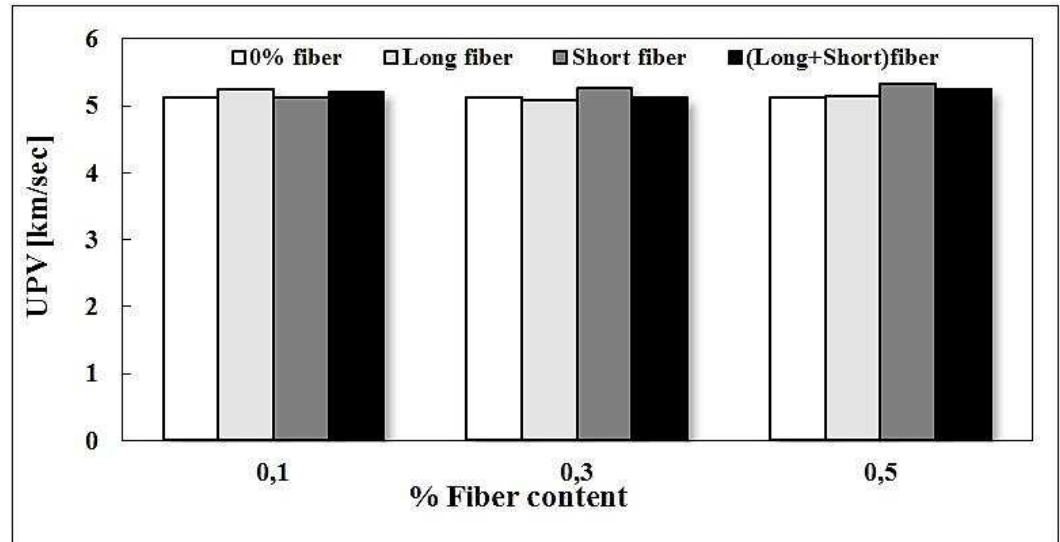

Fig. 14: Ultrasonic pulse velocity of concrete mixtures at 28 days.

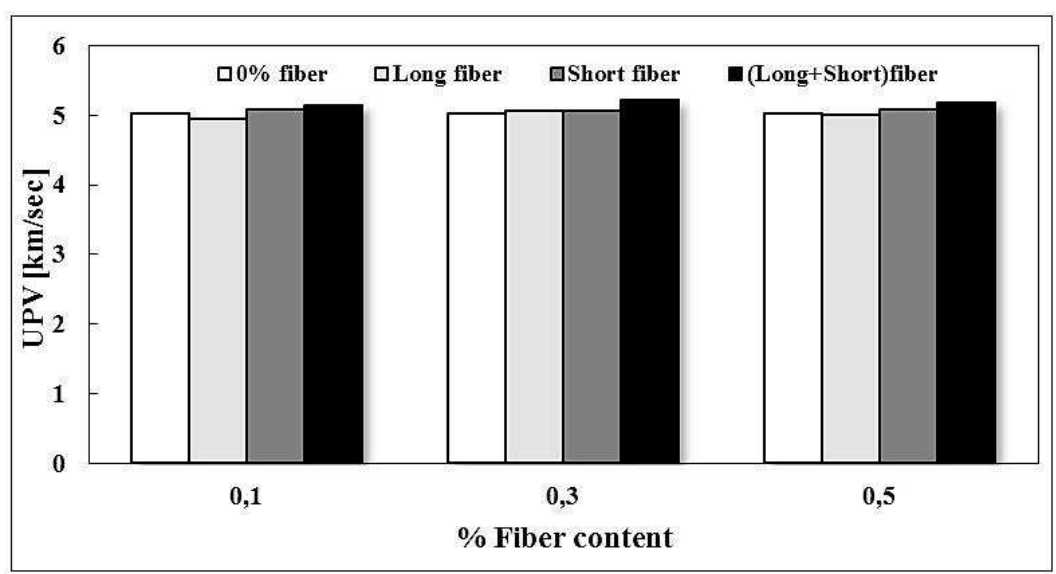

Fig. 15: Ultrasonic pulse velocity of concrete mixtures at 56 days.

It is noticed from the two figures that the inclusion of the PET fibers did not negatively influence the microstructure of the concrete, as this significant effect on the results was not observed. Whereas, 
according to the standard of concrete classification based on the results of ultrasound pulse velocity test shown in Table 8 [29], it can be concluded that concrete containing PET fibers are excellent concrete mixtures when compared with references [29].

Table 8: Concrete classification based on ultrasound pulse velocity [29].

\begin{tabular}{|c|c|}
\hline Pulse velocity [m/s] & Concrete classification \\
\hline $\mathrm{V}>4500$ & Excellent \\
\hline $4500>\mathrm{V}>3500$ & Good \\
\hline $3500>\mathrm{V}>3000$ & Questionable \\
\hline $3000>\mathrm{V}>2000$ & Poor \\
\hline $\mathrm{V}<2000$ & Very Poor \\
\hline
\end{tabular}

Figs. 16 and 17 show the relationship between compressive strength and Ultrasound Pulse Velocity (UPV) testing for concrete containing PET fiber waste and for ages 28 and 56 , respectively. It can be noticed that there is a slight decrease in the UPV values with an increase in the content of plastic fibers waste. This can be attributed to the reason that the speed of ultrasound is affected by the heterogeneity of the concrete as it passes through several components that make up the concrete (aggregates, cement paste, plastic fibers waste, and voids), which it leads to a reflection or partial transmission of the wave and thus reduces its velocity. As it is known that UPV is a function of the volumetric concentration of the concrete components [30]. Therefore, the slight decrease in the wave velocity is due to a slight increase in the porosity of the concrete due to the increase in the developed voids between the aggregate grains, cement paste and the fibers. This can be attributed due to incomplete mixing thus free water is formed [31]. However, despite this slight decrease in the UPV values, concrete containing PET waste is still classified among the excellent categories of concrete. Besides, it can be seen that polynomial correlation was used to determine the relationship between UPV and compressive strength for concrete mixes containing plastic fiber wastes at ages 28 and 56 days. The results revealed a statistically perfect relationship between UPV and compressive strength. This is evident from the coefficient of determination (R-squared), especially at the age of 56 days. This is due to a previously mentioned reason that PET wastes are hydrophobic and prevent its permeability during the treatment, which affects the rehydration process. While by continuing the treatment for 56 days, the compressive strength increases due to the completion of rehydration compounds as this will reduce the voids in the concrete texture, and makes the wave travel more continuously without interruption. Moreover, ultrasound is closely related with dense concrete where the denser concrete means less time for the wave to pass.

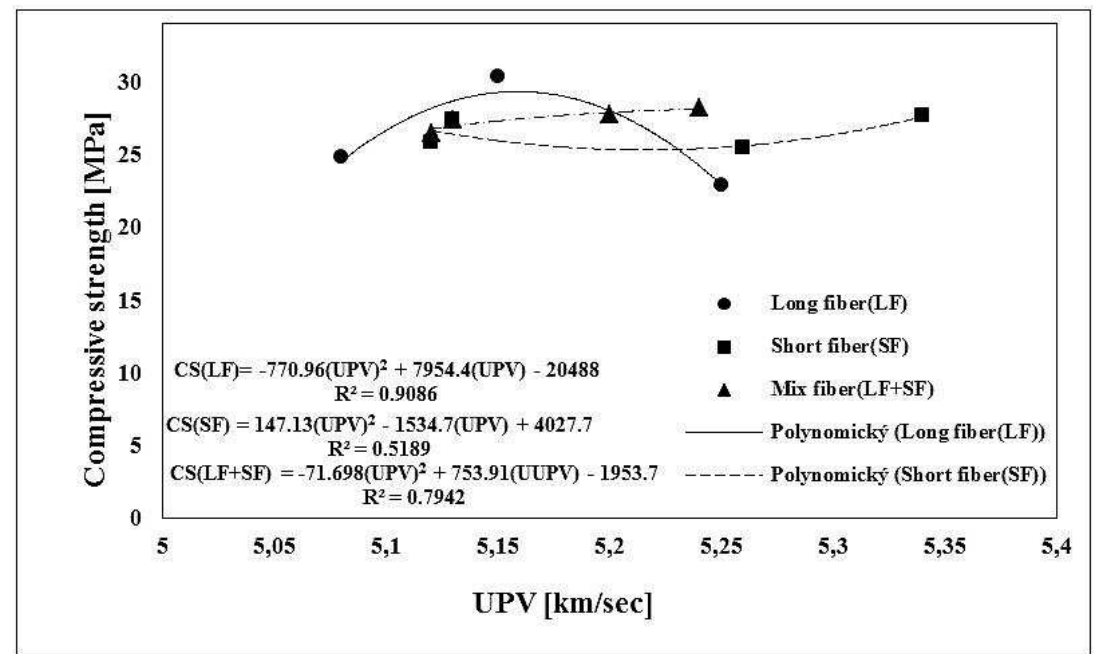

Fig. 16: Relationship between compressive strength and ultrasound pulse velocity at age 28 days. 


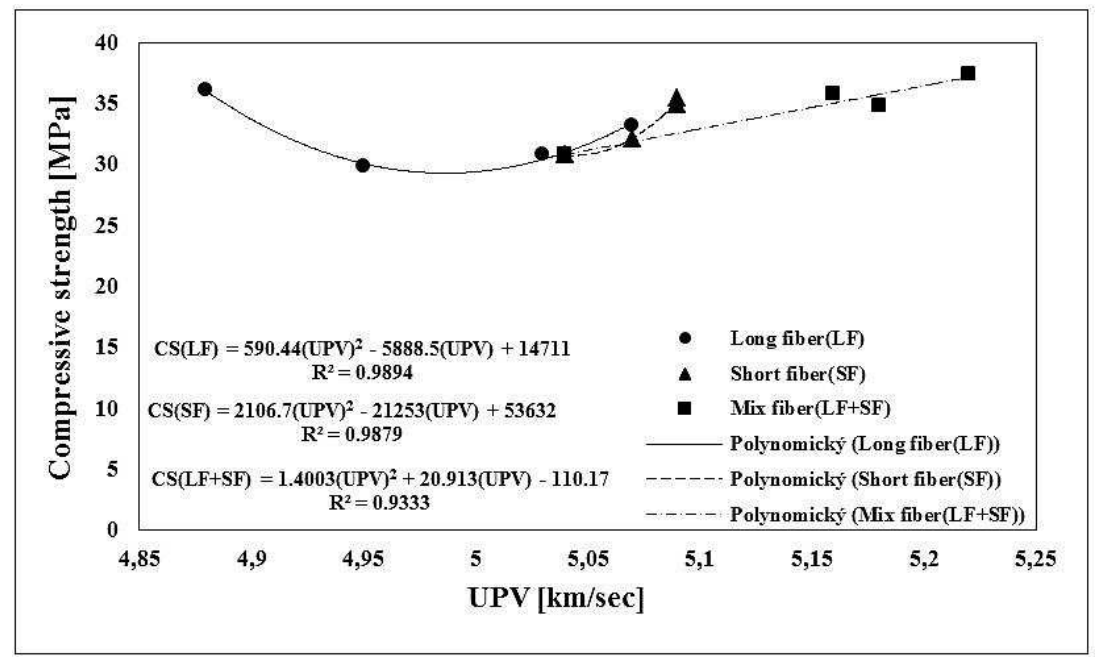

Fig. 17: Relationship between compressive strength and ultrasound pulse velocity at age 56 days.

\section{Summary and conclusions}

In this study, an attempt was launched to experimentally evaluate the mechanical properties of concrete with recycled plastic wastes. Accordingly, 10 concrete mixtures were cast with weight ratios cement: sand: gravel that are 1:2: 4 and with a constant water/cement ratio of 0.58 . One of the mixes was without plastic fibers, as it is considered the reference mix. The other 9 mixtures were divided into three groups, the only variables were the dimensions of the plastic fibers. A variety of experiments were conducted on concrete mixtures such as slump test, compressive test, splitting tensile test, flexural test, and ultrasound pulse velocity test. The most notable findings are summarized as follow:

1) This study demonstrated the possibility of incorporating plastic wastes in the form of fibers into concrete and achieving adequate compressive strength. On the other hand, the use of these wastes in concrete saves the environment and energy.

2) It can be clearly noticed that the addition of PET fibers has a negative effect on the workability of the concrete mixtures. The concrete mixture with $0 \%$ of PET wastes has the highest slump value of $120 \mathrm{~mm}$, and with the addition of PET wastes, the workability gradually decreased. Generally, it is possible to overcome this problem by using plasticizers.

3) It can be concluded from the results that the addition of PET fibers has a slight impact on improving the compressive strength of concrete. Besides, it was observed that all concrete mixes have the same trend as the compressive strength increases with age.

4) The test results at the age of 28 days revealed that the tensile strength of concrete with PET fibers had a clear reduction for all fiber lengths and for all addition ratios. The most significant decrease in the tensile strength of concrete occurred when adding the mixed fibers, which reached $19.17,21.3$, and $23.7 \%$ when adding the fibers in percentages of $0.1,0.3$, and $0.5 \%$, respectively.

5) At a ratio of $0.1 \%$ of PET fibers addition, an improvement was observed in the flexural strength of concrete. While after this ratio, the flexural strength decreased with increasing the percentages of PET wastes. The reason is the inclusion of these fibers led to a weak bond between the fibers and concrete ingredients.

6) When comparing the results of the ultrasound test with the results of previous studies and regulations, it becomes clear that the normal concrete containing plastic wastes in the form of fibers is at an excellent level.

7) The results of ultrasound pulse velocity test showed that the addition of the PET fibers did not negatively affect the microstructure of the concrete.

8) The polynomial relationship between UPV and compressive strength of the concrete mixes showed a suitable and approximate estimate to compare their results. This is evident from the $R^{2}$ values, which range between 52 - $90 \%$ and 93 - $98 \%$ for ages 28 and 56 days, respectively.

\section{References}

[1] NADIMALLA, A. - MASJUKI, S. A. - SAAD, A. B. - ISMAIL, K. M. - ALI, M. B.: Polyethylene Terephthalate (PET) Bottles Waste as Fine Aggregate in Concrete. Int. J. Innov. Technol. Explor. Eng. 8, 2019. 
[2] LEE, Z. H. - PAUL, S. C. - KONG, S. Y. - SUSILAWATI, S. - YANG, X.: Modification of Waste Aggregate PET for Improving the Concrete Properties. Adv. Civ. Eng. 2019, pp. 1-11, https://doi.org/10.1155/2019/6942052.

[3] DINESH, Y. - RAO, C. H.: Strength Characteristics of Tics of Fibre Reinforced Concrete Using Recycled Reinforced Concrete Using Recycled PET. Int. J. Civ. Eng. Technol. 8, 2017, pp. 92-99.

[4] ALFAHDAWI, I. H. - OSMAN, S. A. - HAMID, R. - AL-HADITHI, A. I.: Utilizing Waste Plastic Polypropylene And Polyethylene Terephthalate As Alternative Aggregates To Produce Lightweight Concrete: A Review. J. Eng. Sci. Technol. 11, 2019, pp. 1165-1173.

[5] AKÇAÖZOG ${ }^{\circ} L U$, S. - ATIS, C. D. - AKÇAÖZOG LU, K.: An investigation on the use of shredded waste PET bottles as aggregate in lightweight concrete. Waste Manag. J. 30, 2010, pp. 285-290.

[6] IRWAN, J. M. - ASYRAF, R. M. - OTHMAN, N. - KOH, H. B. - ANNAS, M. M. K. - FAISAL, S. K.: The Mechanical Properties of PET Fiber Reinforced Concrete From Recycled Bottle Wastes. Adv. Mater. Res. 795, 2013, pp. 347-351.

[7] BATAYNEH, M. - MARIE, I. - ASI, I.: Use of Selected Waste Materials in Concrete Mixes, Waste Manag, 27, 2007, pp. 1870-1876.

[8] RAHMANI, E. - DEHESTANI, M. - BEYGI, M. H. - ALLAHYARI, H. - NIKBIN, I. M.: On the mechanical properties of concrete containing waste PET particles. Constr. Build. Mater. 47, 2013, pp. 1302-1308.

[9] AZHDARPOUR, A. M. - NIKOUDEL, M. R. - TAHERI, M.: The Effect of Using Polyethylene Terephthalate Particles on Physical and Strength-Related Properties of Concrete. A Laboratory Evaluation, Constr. Build. Mater. J. 109, 2016, pp. 55-62.

[10] HAMA, S. M. - HILAL, N. N.: Fresh Properties of Self-Compacting Concrete With Plastic Waste as Partial Replacement of Sand, Int. J. Sustain. Built Environ. 6, 2017, pp. 299-308.

[11] KIM, S. B. - YI, N. H. - KIM, H. Y. - KIM, J. J. - SONG, Y.: Material and Structural Performance Evaluation of Recycled PET Fiber Reinforced Concrete. Cem. Concr. Compos. J. 32, 2021, pp. 232-240.

[12] KOO, B.M. - KIM, J. J. - KIM, S. - MUN, S.: Material and Structural Performance Evaluations of Hwangtoh Admixtures and Recycled PET Fiber-Added Eco-Friendly Concrete for CO2 Emission Reduction. Materials (Basel). 7, 2014, pp. 5959-5981.

[13] I.S.S. No. 5, Properties of Ordinary Portland Cement, Iraq, 1984.

[14] A.D. C33, Standard Specification for Concrete Aggregates, Annu. B. ASTM Stand, 2015.

[15] P. 116 BSI BS 1881, Testing concrete, method fordetermination of compressive strength of concrete cubes, 1983, BSI, London.

[16] C. ASTM C496, Standard test method for splittingtensile strength of cylindrical concrete specimens, ASTM Int. Conshohocken, 2017.

[17] C. ASTM C293, Standard test method for flexuralstrength of concrete (using simple beam with center-point loading), ASTM Int. West Conshohocken, 2016.

[18] C.A. C143, Standard test method for slump of hydraulic-cement concrete, West Conshohocken, 2015.

[19] USMANI, M. U. - AWAL, A. S. M.: Physical, Mechanical And Durable Characteristics Of Concrete Incorporating Polyethylene Terephthalate Fiber From Bottle Waste. J. Crit. Rev. 7, 2020, pp. 908-916.

[20] ROMUALDI, G. - BATSON, J.: The Mechanic of Crack Arrest in Concrete, Proceeding Am. Soc. Civ. Eng. 1963.

[21] SOROUSHIAN, R. S. - PLASENCIA, J.: Assessment of Reinforcing Effects of Recycled Plastic and Paper in Concrete. ACI Mater J. 100, 2003.

[22] YIN, N. S. - TULADHAR, R. - SHI, F. - COMBE, M. - COLLISTER, T.: Use of Macro Plastic Fibres in Concrete: A Review. Constr. Build. Mater. 93, 2015, pp. 180-188.

[23] AL-HASHMI, E. A.: Use of Waste Plastic in Concrete Mixture as Aggregate Replacement. Waste Manag. 28, 2008, pp. 2041-2047.

[24] RAI, B. - RUSHAD, S. T. - KR, B. - DUGGAL, S. K.: Study of Waste Plastic Mix Concrete with Plasticizer. Int. Sch. Res. Not. 2012, 2012, https://doi.org/10.5402/2012/469272.

[25] TAHERKHANI, H.: An Investigation on the Properties of the Concrete Containing Waste PET Fibers. Int. J. Sci. Eng. Investig. 3, 2014, pp. 37-43.

[26] BAJAD, M. N.: Basalt Fibre Reinforced Concrete Unprotected to Chemical Attack. Civ. Environ. Eng. 16, 2020, 131-137, https://doi.org/10.2478/cee-2020-0013.

[27] AHAD, M. Z. - ASHRAF, M. - KUMAR, R. - ULLAH, M.: Thermal, Physico-Chemical, and Mechanical Behaviour of Mass Concrete with Hybrid Blends of Bentonite and Fly Ash. Materials (Basel). 12, 2019, pp. 1-14. 
[28] JONES, R. - FACAOARU, I.: Recommendation for Testing Concrete by the Ultrasonic Pulse Method. Mater. Constr. 2, 1969.

[29] NEVILLE, A.: Properties of Concrete, 3rd ed., Burnt Mill, Harlow, Essex, England, Longman Scientific \& Technical, 1981.

[30] ALBANO, C. - CAMACHO, N. - HERNÁNDEZ, M. - MATHEUS, A. - GUTIÉRREZ, A.: Influence of Content and Particle Size of Waste Pet Bottles on Concrete Behavior at Different W/C Ratios. Waste Manag. 29, 2009, pp. 2707-2716, https://doi.org/10.1016/j.wasman.2009.05.007.

[31] NEMATZADEH, M. - POORHOSEIN, R.: Estimating Properties of Reactive Powder Concrete Containing Hybrid Fibers Using UPV. Comput. Concr. 20, 2017, pp. 491-502, https://doi.org/10.12989/cac.2017.20.4.491. 